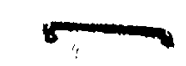

NASA Technical Memorandum 87341

$$
14-7483
$$

\title{
Computational Simulation of Progressive Fracture in Fiber Composites
}

(NASA-TM-87341) COMPUT ATIONAI SIHULATION OF PROGRESSIVE FIACTURE IN FIBER CCMEOSITES

(NASA) $12 \mathrm{P} \mathrm{HC} \mathrm{AO2/MF} \mathrm{AO1} \mathrm{CSCL} 11 \mathrm{D}$

N $86-2637.6$

$\begin{aligned} G 3 / 24 & \begin{array}{l}\text { Unclas } \\ 43288\end{array}\end{aligned}$

Christos C. Chamis

Lewis Research Center

Cleveland, Ohio

Prepared for the

International Conference on Computational Mechanics sponsored by the International Committee on Computational Mechanics Tokyo, Japan, May 25-28, 1986 
COMPUTATIONAL SIMULATION OF PROGRESSIVE FRACTURE IN FIBER COMPOSITES

\author{
Christos C. Chamis \\ Nationa 1 Aeronautics and Space Administration \\ Lewts Research Center \\ Cleveland, onio 44135
}

\title{
SUMMARY
}

Computational methods for simulating and predicting progressive fracture in fiber composite structures are presented. These methods are integrated into a computer code of modular form. The modules include composite mechanics, finite element anaiysis, and fracture criteria. The code is used to computa-

\& tionally simulate progressive fracture in composite laminates with and without defects. The simulation tracks the fracture progression in terms of modes initiating fracture, damage growth, and imminent global (catastrophic) laminate fracture.

\section{INTRODUCTION}

Prediction of progressive fracture of composite laminates is fundamental to developing the methodology for quantifying composite structural durability and rellability. NASA Lewis Research Center is conducting fundamental theoretical and experimental research programs to develop formal methods and procedures for determining progressive composite fracture. The theoretical studies include the development of composite mechanics, combined stress fallure criterla, criterta for identifying predominant fracture modes and assoclated fracture surfaces, and the development of integrated computer codes for the computational simulation of progressive fracture in fiber composites. The experimental studies include development of methods for real time ultrasonic C-scan of laminates under inad in order to detect fracture initiation, damage growth and fracture progression as these events occur. The experimental studies also include development of methods for post-mortem examination of fracture surfaces in order to identify and catalog unique fracture surface characteristics assoclated with dominant fracture modes.

The theoretical studies previously mentioned led to the development of computational methods for assessing composite structural behavior (integrity, durabllity and damage tolerance). A major portion of the computational method: development includes the computational simulation of progressive fracture in composites which is the subject of inis paper. This simulation is described in terms of (1) the various composite scales (as defined later) and types of fracture modes that occur in these scales. (2) an integrated computer code to perform the simulation, and (3) application of the code to predict progressive laminate fracture.

\section{FUNDAMENTAL CONSIDERATIONS}

Progressive fracture in fiber composites is a dynamic (real-time) physical process. This process is an accumulation of multiple events triggered by the vartous stress states and their attendant fallure modes present in fiber composttes. The varlous fallure modes take place at different scales (leveis) in 
the composite. The different levels include: (1) sub-micro scale (intra or within each constituent and the interphase), (2) micro scale (inter-constftuent). (3) macro scale (individual plies and interplies), (4) laminate scale (ali plies in a line through the thickness of the laminate). (5) local scale, a small region defined by neighboring points in the laminate piane (for example, nodes connecting a finite element) and, (6) global scale (the structural component).

Because of the several faliure modes in each scale, fracture can occur as single events at different times in different locations in the composite structure. Or it can occur simultaneousiy as multiple events in one or more locations in the romposite structures. In view of this, it is convenient to discuss progressive fracture using the following definitions: (1) fallure initiation - when the stress field induces a faflure in the sub-micro scale, (2) defect or riaw formation - when one or more sub-micro scale fallures coalesce to form a micro scale fallure, (3) ply fallure - when several micro defects coalesce to form defects in the macro scale (transply cracks), (4) delamination - when a defect is formed between adjacent plies, (5) laminate fallure - when macro defects (transply cracks) coalesce to form a through-thethickness laminate defect or crack, (6) progressive fracture - when laminate defects progress in the plane of the laminate to form defects in the local scale, and (7) global fracture - when the composite structure fractlires in one or more parts. Events occurring in items (1) to (6) are usualiy combired and are collectively called laminate or composite damage.

Computational simulation of progressive fracture in composites as a realtime dynamic event has not yet been investigated to the author's knowledge. Also, computational simulation of progressive fracture as an equivalent static process starting from the sub-micro scale has not yet been investigated. The computational simulation presently pursued at Lewis is based on the macro scale and it assumes that progressive fracture is an equivalent static process. In this computational simulation, macro scale defects (transply cracks) are formed when the stress fleld induces fallure in one of the ply fallure modes (longitudinal tension or compression, transverse tension or compression and intralaminar shear) and/or induces interply delamination. The corresponding ply and interply strengths are predicted using composite micromechanics. The composite micromechanics account for vold and hygrothermal effects on the constituents and, therefore, on the ply and interply strengths. Composite micromechanics integrate, in part, the events occurring at the sub-micro and micro scales.

\section{COMPUTATIONAL SIMULATION USING CODSTRAN}

Research activities on progressive composite fracture at Lewis during the last ten years have culminated in the development of the CODSTRAN computer code (ref. 1). CODSTRAN (Composite Durability Structural Analysis) has been specifically developed for the computational simulation of progressive fracture in ftber composites.

CODSTRAN is a modular program (fig. l) that does quantitative calculations to predict defect growth and progressive fracture in composite structural components. Capabilities of CODSTRAN include determining the durability of composites with and without defects, determining structural responses due to mechantcal and thermal loads, accurate prediction of stress states near defects (stress concentrations), and prediction of ply and laminate level 
fallure and fracture. The modules comprising CODSTRAN are: (1) the executive module, containing communication links to all other modules; (2) the $1 / 0$ module; (3) the Analysis module; (4) the Composite Mechanics Module; and (5) the Fracture Mechanics module.

The Analysis module is NASTRAN (ref. 2) and is used to calculate both near-field and far-field stresses in a fintte element model of the structural component or specimen. The Composite Mechanics module (MFCA) (ref. 3) generates laminate properties from constituent properties (composite micromechanics) and uses intraply fallure and interlaminar delamination criteria to check ply and interply fallure, respectively. The Fracture Mechanics module is able to account for both ply level fracture and laminate fracture. The modified distortion energy principle and/or a general quadratic surface fit are used to indicate combined ply level fracture (ref. 4). Laminate level fallure is based on concepts described in references 5 and 6 . It is assumed to occur when all the plies in the laminate have falled.

To computationaliy simulate progressive fracture, CODSTRAN uses an iterative procedure whereby a load is applied to the finite element mesh of the structure being modeled. The response of the structure to the load can be no damage, damage, or destruction of an element(s) (local fracture). Based upon this response, the load increment is updated as follows: (1) if no damage is predicted, the load is updated by some predetermined load increment; (2) if elements are damaged or destroyed (defect growth or local fracture), the same load is re-applied with reduced materlal properties assigned to the damaged elements. Destroyed elements are purged from the finite element mesh, effectively defining progressive fracture. This load is maintained until equilibrium in the structure is achieved. Equllibrium is defined as the point where the structure, with its updated geometry and modified material properties, can sustaln the applied load without the occurrence of further damage. This iterattve procedure is continued through load increments until global fracture of the structure occurs. This iterative procedure is deplcted scheriatically in figure 2 .

\section{PROGRESSIVE FRACTURE - TYPICAL RESULTS}

CODSTRAN has been used to computationally simulate progressive fracture in a composite laminate with a center notch depicted schematically in figure 3 (ref. 1). These laminates were made from Thornel 300 graphite fiber in an epoxy matrtx (T300/E). The laminate configuration is $[0 /+30 / 0 /-30 / 0]$ ss with about $0.005 \mathrm{in}$. ply thickness. These types of laminates were loaded to fracture in axial tension. The finite element model used in the simulation is shown in figure 4.

Progressive damage and fracture results obtalned are sumarized in figure 5 at several load levels indicated as a percentage of the fracture load. First damage indication appeared at 33 percent of the load. The damage continued to grow and extend untll the load was increased to 100 percent of the fracture load. At this load CODSTRAN looped through several iterations. The first iteration, caused the extended damage shown in the first 100 percent schematic in figure 5. The last 1teration destroyed all elements to the right of the cracks, indicating laminate global fracture with some bending as shown in the last schematic in figure 5. 
CODSTRAN has also been used to study the damage growth and progressive fracture of laminates without defects, with center silts and with center holes (refs. 7 and 8 ). Progressive fracture results from this study are summarized in figure 6 at zero load and at fracture load, first iteration. As can be seen the progressive fracture is about the same for the laminates with the slit and with the hole. It is interesting to nota that progressive fracture initiated at the center of the laminate without defects and advanced in generaliy similar directions as that in the laminates with the defects.

CODSTRAN keeps records of all the modes that initiate fracture at the macroscale (ply and interply) levels. A typical output of these records is summarized in Table I for the laminates shown in figure 6 and for different laminate configurations $\left[ \pm \theta_{s}\right]$. These results provide considerable details with respect to weak modes in the laminate and with respect to its structural integrity and/or damage tolerance. In addition to records of fracture modes, CODSTRAN keeps records of plies destroyed, elements destroyed and nodes which do not connect elements. All this information is necessary to track the damage (defect growth and progressive fracture) at the varlous scales within which it occurs.

In order to assess the fracture toughness and service life of the laminate, CODSTRAN continued to track the crack or defect opening in either the local scale (between two adjacent nodes) or global (overall displacements) scale. Typical results for local crack opening displacement in laminates with center silts are shown in figure 7 for two laminate configurations. The results for the $[ \pm 45]_{s}$ laminate show unbounded crack opening displacement for the same load and, therefore, imminent giobal (catastrophic) fracture once progressive fracture began. The resuits for the $[0]_{4}$ laminate showed several increases in load were required prior to imminent global (catastrophic) fallure.

\section{CONCLUSIONS}

Progressive fracture in fiber composites can be computationally simulated using an integrated computer code such as CODSTRAN. The computational simulation tracks fallure inftlation, defect growth and damage, at the varlous scales in which these events occur. The computational simulation of progressive fracture provides extensive detailed information which can be used to detect fallure initiation modes, damage growth (magnitude and direction), progressive fracture direction, and imminent global fracture. All this information makes it possible to computationally assess the structural integrity, damage tolerance and service life of fiber composite structures.

\section{REFERENCES}

1. Chamis, C.C.; and Smith, G.T.: CODSTRAN: Composite Durability Structural Analysis. NASA TM-79070, 1978.

2. McCormick, C.W., ed.: NASTRAN Useŕ:s Manual (level 15). NASA SP-222(01), 1972.

3. Chamis, C.C.: Computer Code for the Analysis of Multilayered Fiber Composites - User's Manual. NASA TN D-7013, 1971. 
4. Chamis, C.C.: Fallure Criteria for Filamentary Composites. Composite Materials: Testing and Design, ASTM-STP-460, ASTM, 1969, pp. 336-351.

5. Sinclatr, J.H.; and Chamis, C.C.: Fracture Surface Characteristics of Off-Axis Composites. NASA TM-73700, 1977.

6. Sinclair, J.H.; and Chamis, C.C.: Mechantcal Behavior and Fracture Characteristics of Off-Axts Ftber Composites. I - Experimental Investigation. NASA TP-1081, 1977.

7. Irvine, T.B.; and Ginty, C.A.: Progressive Fracture of Fiber Composites. NASA TM-83701, 1983.

8. Ginty, C.A.; and Irvine, T.B.: Fracture Surface Characteristics of Notched Angleplied Graphite-Epoxy Composites. NASA TM-83786, 1984. 
TABLE I. - FRACTURE MODE $\mathrm{a}$ OF $[ \pm \theta]_{S}$ G/E LAMINATES

(PREDICTED BY CODSTRAN)

\begin{tabular}{|c|c|c|c|c|c|c|c|c|c|c|}
\hline \multirow[b]{2}{*}{ Notch type } & \multicolumn{10}{|c|}{ Ply configuration: $[ \pm \theta]_{s} ; \theta$ in degrees } \\
\hline & 0 & 3 & 5 & 10 & 15 & 30 & 45 & 60 & 75 & 90 \\
\hline $\begin{array}{l}\text { Unnotched } \\
\text { soltd }\end{array}$ & LT & $\begin{array}{l}\text { LT } \\
S^{3}\end{array}$ & $\begin{array}{l}\text { LT } \\
S^{3}\end{array}$ & $\begin{array}{l}L T \\
S^{3}\end{array}$ & $\begin{array}{l}I \\
S\end{array}$ & $\mathbf{S}$ & $\begin{array}{l}I \\
S\end{array}$ & $T T$ & TT & TT \\
\hline $\begin{array}{l}\text { Notched } \\
\text { thru slit }\end{array}$ & $\begin{array}{l}\text { LT } \\
S^{T}\end{array}$ & $\begin{array}{l}L T \\
S\end{array}$ & $\begin{array}{l}L T \\
S\end{array}$ & $\mathbf{S}$ & $\mathbf{S}$ & I & $\begin{array}{l}I \\
S\end{array}$ & $\begin{array}{l}I \\
T T \\
S^{2}\end{array}$ & TT & TT \\
\hline $\begin{array}{l}\text { Notched } \\
\text { thru hole }\end{array}$ & $\begin{array}{l}L T \\
S\end{array}$ & $\begin{array}{l}L T \\
S\end{array}$ & $\begin{array}{l}\text { LT } \\
S\end{array}$ & $\mathbf{S}$ & $\begin{array}{l}S \\
L T\end{array}$ & I & $\begin{array}{l}\text { I } \\
\text { S } \\
\text { TT }\end{array}$ & $\begin{array}{l}I \\
\text { TT }\end{array}$ & $T T$. & TT \\
\hline
\end{tabular}

${ }^{a} L T=$ Longitudinal tension

$T T=$ Transverse tension

$S=$ Intraply shear: 1) Intraply shear occurring around notch tip during progressive fracture

2) Minimal intraply shearing during fracture

3) Some intraply shear occurring

$I$ = Interply delamination near constraints (grips) 


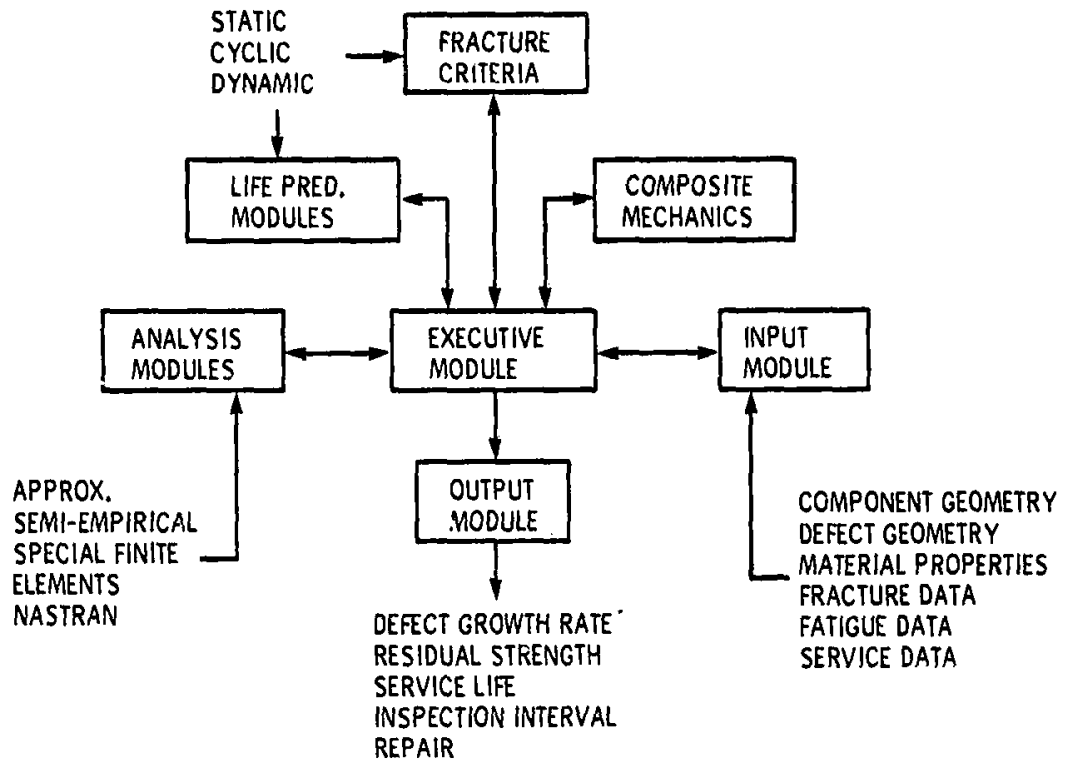

Figure 1. - CODSTRAN computer code schematic.

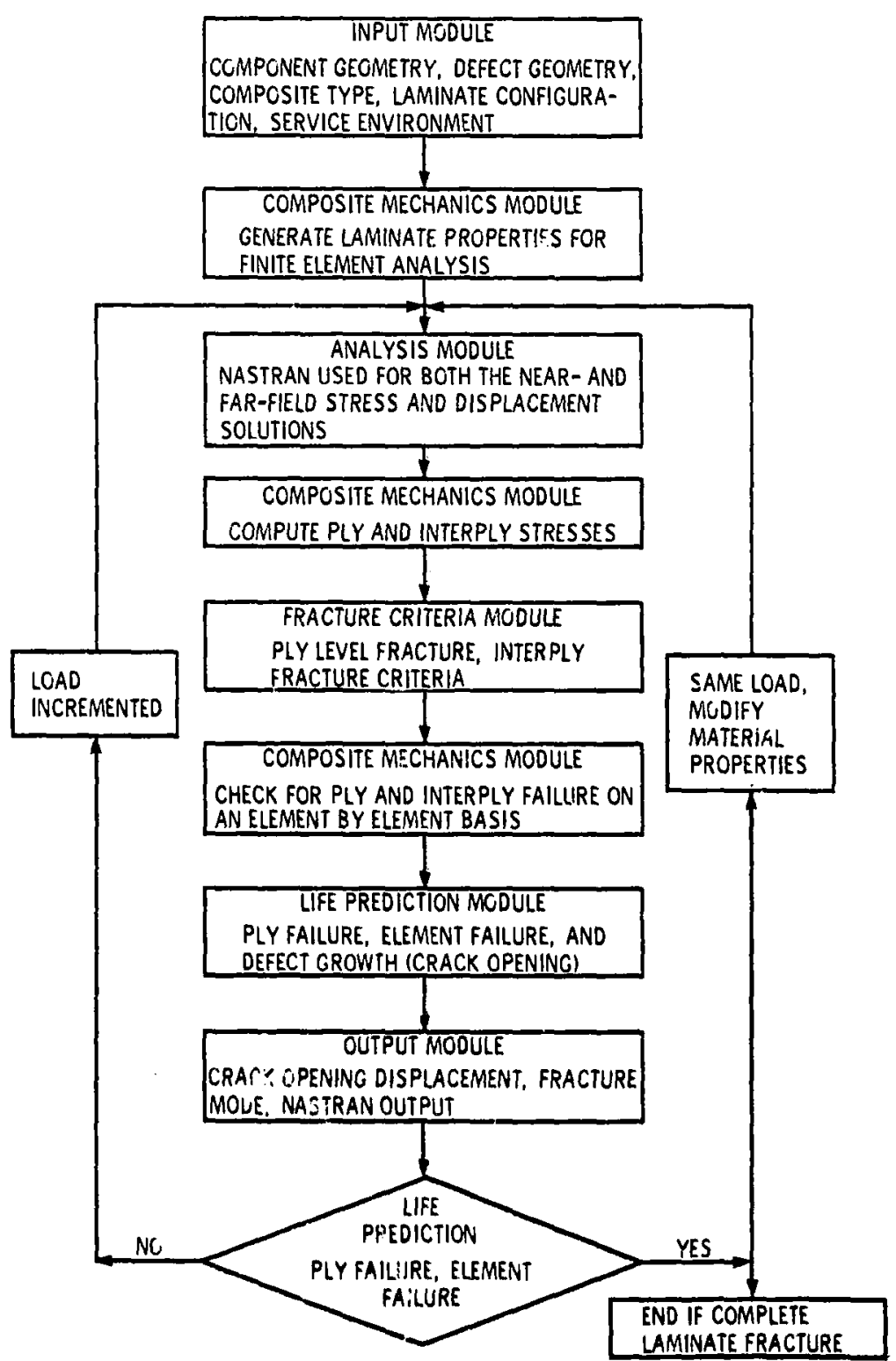

Figure 2. - CODS IKAN flow chart: computational simulation of progressive fracture. 

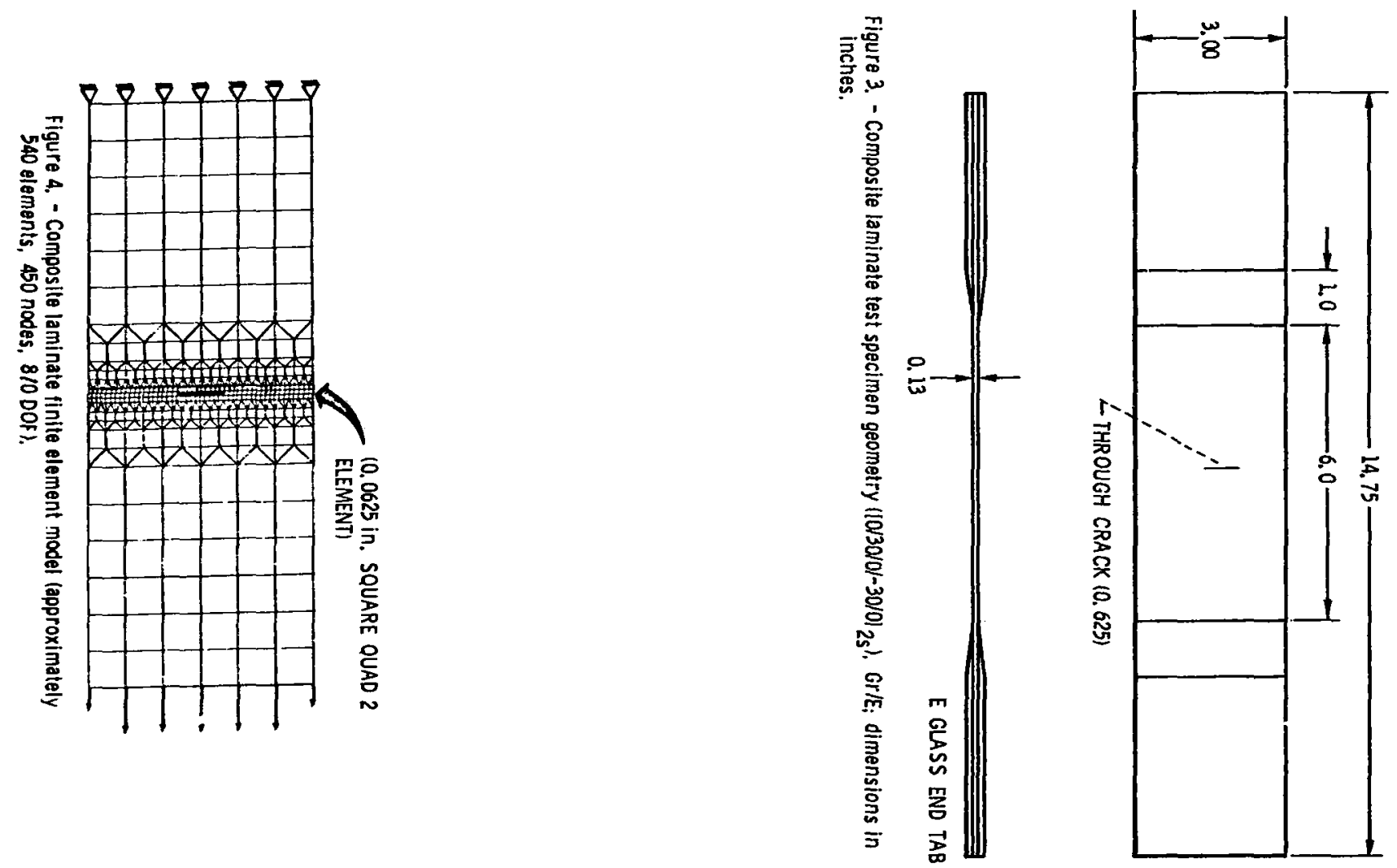


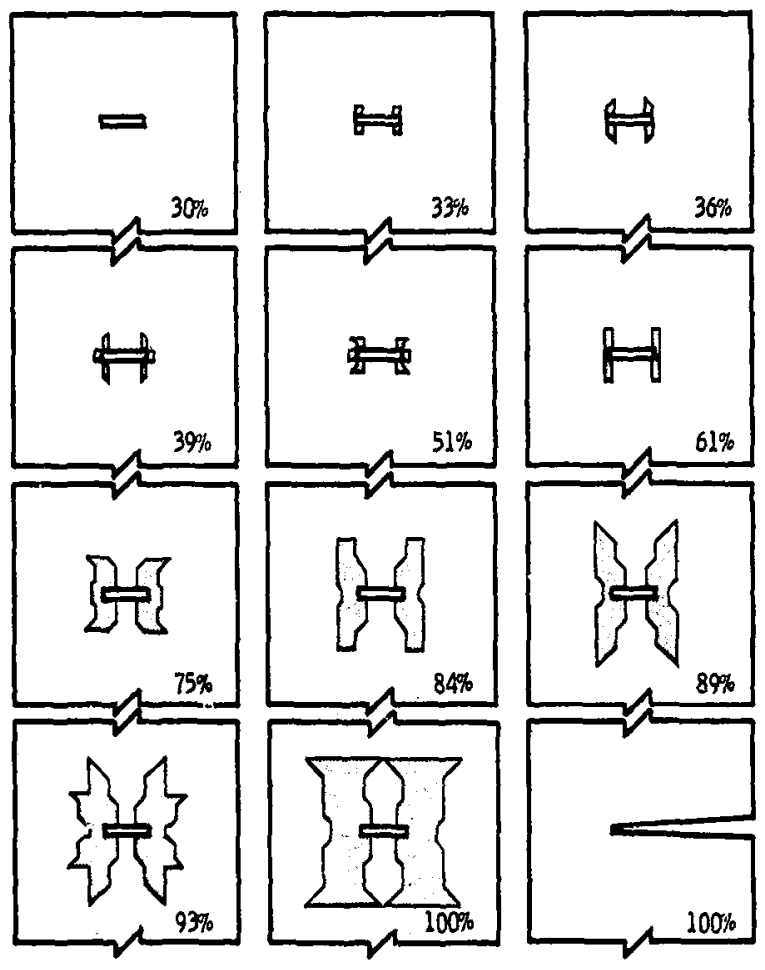

Figure 5. - Computationally simulated progressive fracture at various

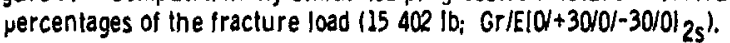


ORICINAL PAGE IS OF POOR QUALIT
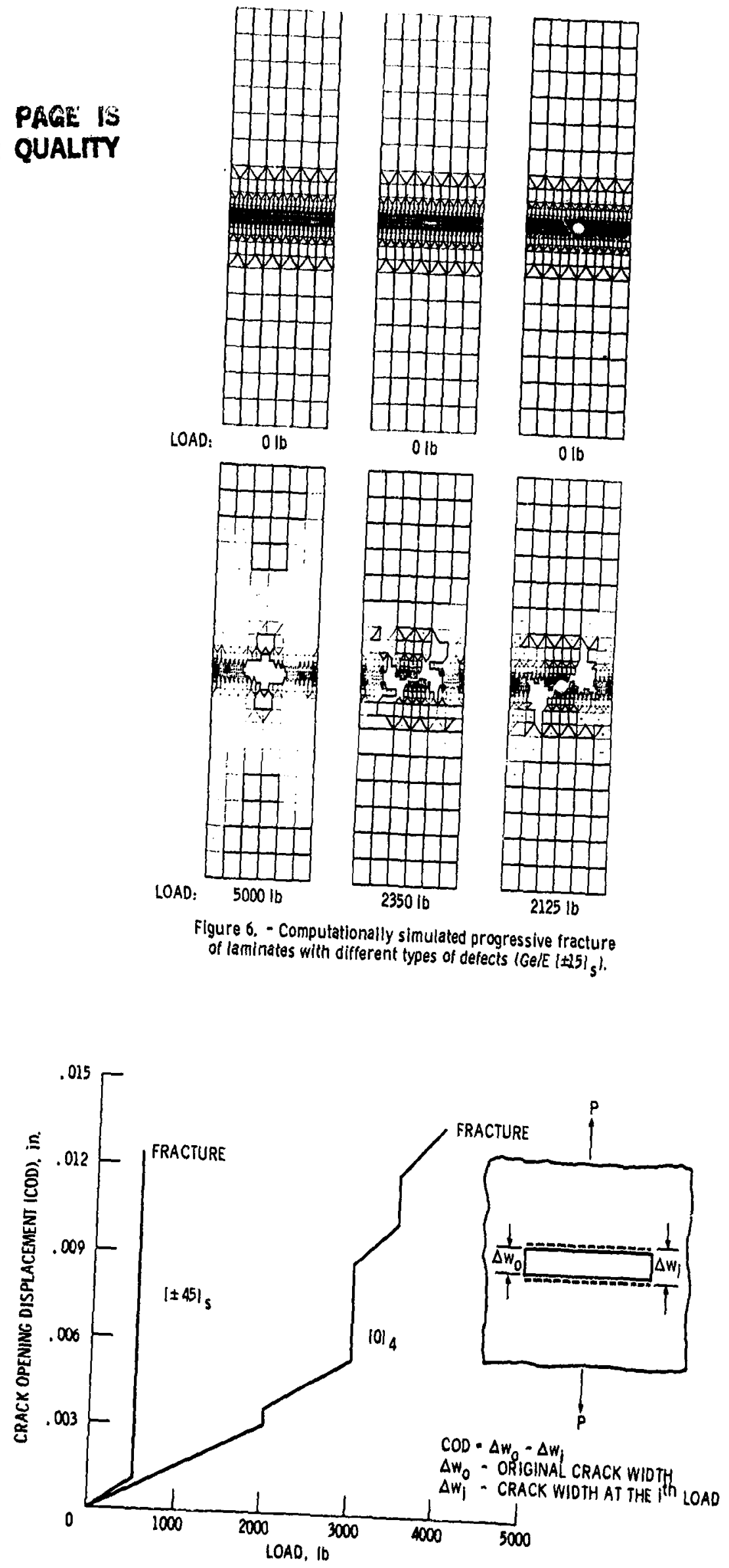

Figure 7. - Compulationally simulated laminate behavior to fracture $\left(\mathrm{Gr} / \mathrm{E} / \pm\left. 8\right|_{5}\right)$. 


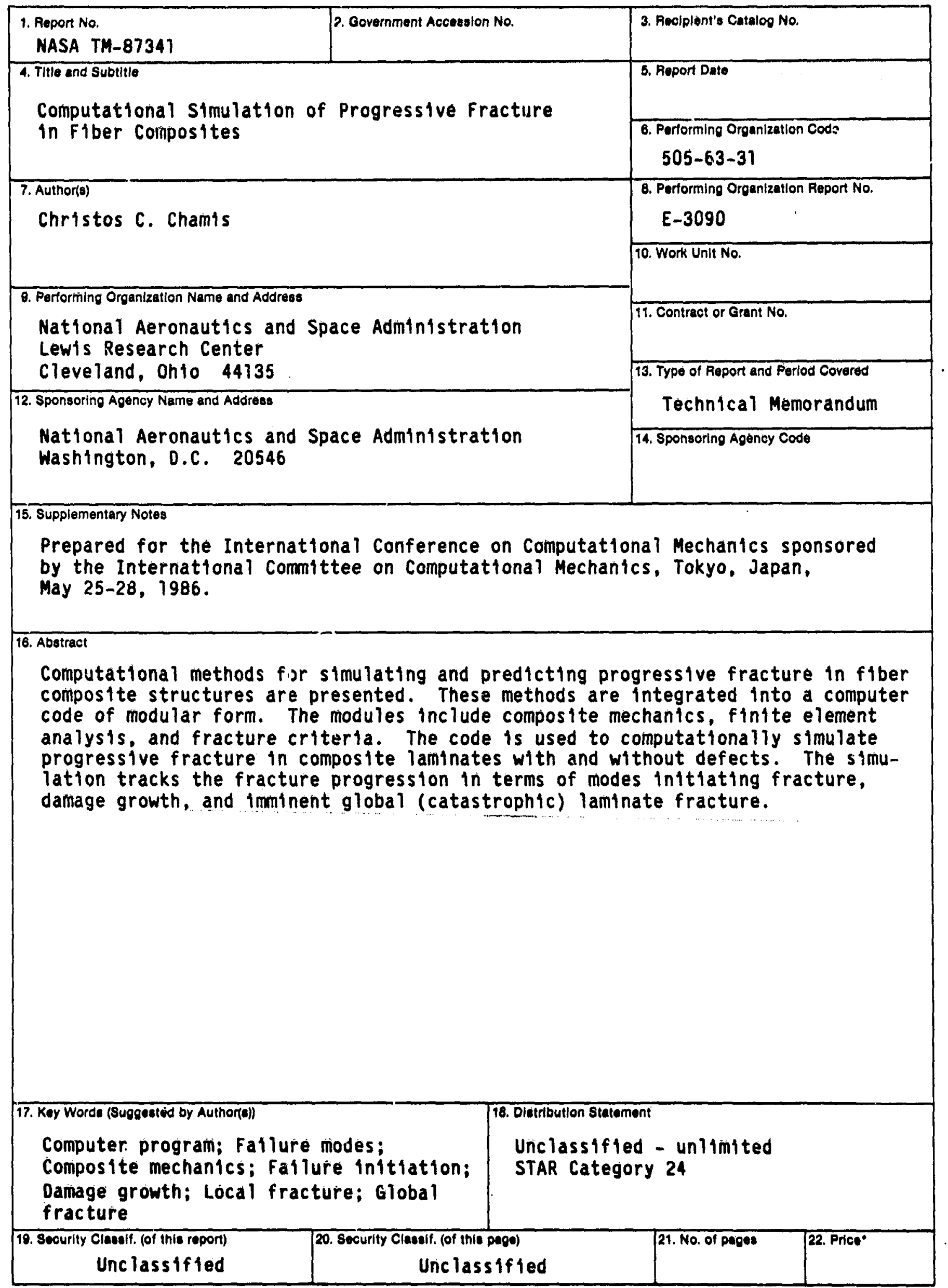

-For sale by the National Technical Inlormation Service, Springfield, Virginia 22161 